\title{
8

\section{O USO DOS APLICATIVOS PHOTOMATH E TOON MATH NO ENSINO DE MATEMÁTICA}

\section{USING PHOTOMATH AND TOON MATH APPLICATIONS IN MATHEMATICS TEACHING}

\author{
Wilamis Micael de Araújo Aviz ${ }^{1}$; Audrey Emmely Rodrigues Vasconcelos ${ }^{2}$, Claudia de \\ Oliveira Lozada ${ }^{3}$
}

\begin{abstract}
RESUMO
Nos últimos anos, as tecnologias móveis têm auxiliado consideravelmente o processo ensinoaprendizagem de Matemática. Além de inovarem os processos educativos com modelos de interação entre o aluno, o conhecimento e o dispositivo, de modo mais dinâmico, constituem um fator de motivação para as aulas de Matemática que geram um efeito positivo no que diz respeito à participação do aluno no processo de aprendizagem. A chamada aprendizagem móvel ou mlearning redefine o espaço educativo trazendo novos recursos didáticos e tipos de interações com o objeto de conhecimento, transpondo a temporalidade e o espaço escolar onde a aprendizagem costuma ocorrer, para além deles. Assim é preciso considerar os saberes referenciais dos alunos e como se estabelecem com o uso das tecnologias na sociedade e no contexto educativo, no sentido de ressignificá-los e reconfigurá-los considerando a imersão na cultura digital. A inserção das tecnologias digitais de informação e comunicação no currículo é prevista desde a década de 90 no sentido de promover novas formas de construção e assimilação do conhecimento, mas ganhou notoriedade no período da pandemia em 2020, em que o isolamento social provocou a suspensão das aulas presenciais e a única forma de promover a continuidade do processo educativo foi o uso das tecnologias digitais de informação e comunicação (TDICs). Assim, o presente artigo, por meio de uma pesquisa qualitativa, teve como propósito apresentar as potencialidades da utilização dos aplicativos Toon Math e Photomath como uma alternativa viável em sala de aula para o processo de ensino-aprendizagem de Matemática. A análise dos aplicativos demonstrou que são ferramentas significativas para o ensino-aprendizagem de Matemática na Educação Básica e no Ensino Superior, fortalecendo práticas pedagógicas inovadoras que devem
\end{abstract}

\footnotetext{
${ }^{1}$ Bacharelando em Engenharia da Computação. Universidade Federal de Alagoas, Maceió, Alagoas, Brasil. Endereço para correspondência: Av. Lourival Melo Mota, S/N, Tabuleiro do Martins, Maceió, Alagoas, Brasil. E-mail: wmaa@ic.ufal.br

iD ORCID iD: https://orcid.org/0000-0002-3610-2426.

${ }^{2}$ Bacharelanda em Ciência da Computação. Universidade Federal de Alagoas, Maceió, Alagoas, Brasil. Endereço para correspondência: Av. Lourival Melo Mota, S/N, Tabuleiro do Martins, Maceió, Alagoas, Brasil. E-mail: aerv@ic.ufal.br

iD ORCID iD: https://orcid.org/0000-0002-7308-1628.

${ }^{3}$ Doutora em Educação (Linha de Pesquisa em Ensino de Ciências e Matemática) - Universidade de São Paulo (USP). Docente da Universidade Federal de Alagoas, Maceió, Alagoas, Brasil. Endereço para correspondência: Av. Lourival Melo Mota, S/N, Tabuleiro do Martins, Maceió, Alagoas, Brasil. E-mail: clalloz@yahoo.com.br

(D) ORCID iD: https://orcid.org/0000-0003-1425-9956.
} 
ser apropriadas pelos professores e utilizadas com frequência tendo como base a racionalidade de relevância proposta por Orozco-Gómez (2002).

Palavras-chave: Ensino de Matemática; Aplicativos; Aprendizagem Móvel.

\begin{abstract}
In recent years, mobile technologies have considerably helped the mathematics teaching-learning process. In addition to innovating educational processes with models of interaction between the student, knowledge and the device, in a more dynamic way, constitute a motivating factor for Mathematics classes that generate a positive effect with regard to student participation in the process of learning. The so-called mobile learning or m-learning redefines the educational space by bringing new didactic resources and types of interactions with the object of knowledge, transposing the temporality and the school space where learning usually takes place, in addition to them. Thus, it is necessary to consider the students' referential knowledge and how they establish themselves with the use of technologies in society and in the educational context, in the sense of reframing and reconfiguring them considering the immersion in digital culture. The insertion of digital information and communication technologies in the curriculum has been foreseen since the 1990s in order to promote new forms of construction and assimilation of knowledge, but it gained notoriety during the pandemic period in 2020, when social isolation caused the suspension of face-to-face classes and the only way to promote the continuity of the educational process was the use of digital information and communication technologies (TDICs). Thus, this article, through a qualitative research, aimed to present the potential of using the Toon Math and Photomath applications as a viable alternative in the classroom for the mathematics teaching-learning process. The analysis of the applications demonstrated that they are significant tools for the teaching-learning of Mathematics in Basic Education and in Higher Education, strengthening innovative pedagogical practices that must be appropriated by teachers and used frequently based on the rationality of relevance proposed by Orozco-Gómez (2002).
\end{abstract}

Keywords: Mathematics teaching; Applications; Mobile Learning. 
Wilamis Micael de Araújo Aviz, Audrey Emmely Rodrigues Vasconcelos e Claudia de Oliveira Lozada $O$ uso dos aplicativos Photomath e Toon Math no ensino de matemática

\section{Introdução}

As tecnologias digitais da informação e comunicação, também conhecidas como TDICs, têm transformado tudo ao nosso redor, desde a nossa forma de se comunicar até a forma de aprendermos algo. As TDICs têm sido incorporadas na Educação como meio para promover aprendizagens mais significativas, como pontua a Base Nacional Comum Curricular (BRASIL, 2018), com o intuito de apoiar os educadores na implementação de metodologias de ensino mais lúdicas e dinâmicas, alinhando o processo de ensinoaprendizagem à realidade dos alunos e despertando maior interesse e engajamento por parte dos mesmos.

É nesse sentido que a BNCC (BRASIL, 2018) coloca a cultura digital como parte do universo escolar na medida em que pode auxiliar na aprendizagem e na construção de novos conhecimentos por meio do uso dos recursos tecnológicos nas aulas, sendo que tais recursos, também contribuem para o letramento e inclusão digital, uma vez que a linguagem digital é bem específica, se dissemina em poucos segundos e estabelece formas novas de comunicação.

Um dos principais recursos que estão à disposição para utilização em sala de aula são os aplicativos educativos, que além de fácil acesso, são atrativos para os alunos, devido à interatividade que estimula ainda mais o aprendizado dos conteúdos. Atualmente diversos aplicativos são capazes de facilitar o entendimento da Matemática ou de qualquer outra disciplina para os alunos, sendo uma ferramenta útil para fixar conteúdos ou para revisar ou reforçar alguns conceitos. Mesmo assim, estes aplicativos não substituem o ensino formal, apenas o complementam para que haja a fixação de conteúdos e a diversificação do método de aprendizagem.

Os aplicativos educativos empregados nas aulas de Matemática auxiliam no desenvolvimento de diversas habilidades e competências cognitivas como o raciocínio lógico para resolução de problemas (CALDER e CAMPBELL, 2016), uma vez que estimulam a concentração e organização do pensamento para se chegar à solução do problema. Além do mais, muitos aplicativos trazem conteúdos contextualizados possibilitando ao aluno perceber as aplicações da Matemática no cotidiano, assim como geram maior autonomia em relação aos estudos uma vez que os alunos podem acessá-los no momento que desejarem e assim refazer as atividades. Quando trazem desafios e jogos 
Wilamis Micael de Araújo Aviz, Audrey Emmely Rodrigues Vasconcelos e Claudia de Oliveira Lozada $O$ uso dos aplicativos Photomath e Toon Math no ensino de matemática

matemáticos, estimulam a tomada de decisões e articulação de estratégias, além de maior engajamento dos alunos.

Por outro lado, embora muitos aplicativos apresentem um caráter lúdico, não devem ser vistos como meio de diversão quando utilizados em sala de aula, mas sim como uma ferramenta para a aprendizagem, que possui uma intencionalidade educativa devendo ser inseridos nas atividades propostas por meio de um planejamento das aulas em que se vise o desenvolvimento de habilidades e competências matemáticas.

Nesse sentido, este trabalho traz uma análise de dois aplicativos que podem ser utilizados nas aulas de Matemática da Educação Básica, identificando suas potencialidades e sugerindo abordagens para seu uso.

\section{Uma visão geral sobre as TDICs no Ensino de Matemática na Educação Básica}

No final da década de 90, a publicação dos Parâmetros Curriculares Nacionais PCNs (BRASIL, 1998) sinalizava que havia uma preocupação com a inserção da tecnologia como ferramenta de ensino na Educação Básica. A ascensão da tecnologia como elemento cada vez mais presente no cotidiano e as inovações curriculares em países da Europa e nos EUA recomendando a sua utilização no ambiente escolar, produziram efeitos nas discussões para reformas curriculares que ocorriam no Brasil, colocando-se inclusive como uma tendência em pesquisas na área de Educação, situando seus usos nos diferentes componentes curriculares.

Nessa época, as discussões giravam em torno do uso do computador nas aulas de Matemática, uma proposta que tinha um vínculo diretamente associado à informática, que representava o contexto mais evidente da tecnologia da época, uma vez que os computadores pessoais e a world wide web se disseminavam além dos escritórios das empresas para os lares, mudando a forma com que as pessoas trabalhavam, interagiam e tinham acesso às informações.

A circulação das informações tornou-se mais rápida assim como a forma com que o conhecimento é construído, reconstruído e compartilhado. Anteriormente, restrito às salas de aula física, grupos específicos e eventos presenciais, a coletivização na construção e disseminação do conhecimento transcendeu esses espaços físicos e formais e se espalhou informalmente em chats, grupos de discussão e espaços para comentários em posts, dando voz a uma diversidade de ideias e posicionamentos, emergindo 
Wilamis Micael de Araújo Aviz, Audrey Emmely Rodrigues Vasconcelos e Claudia de Oliveira Lozada O uso dos aplicativos Photomath e Toon Math no ensino de matemática

singularidades e novas culturas. Assim, surge a cibercultura (LÉVY, 2000) impregnada pela ideia da inteligência coletiva nesses espaços onde a comunicação, interação e circulação das vozes e ideias gera conhecimento e em sua amplitude, o saber, sendo que Lévy (2003, p. 28) define inteligência coletiva como "[...] uma inteligência distribuída por toda parte, incessantemente valorizada, coordenada em tempo real, que resulta em uma mobilização efetiva das competências".

Lévy $(2000,2003)$ com suas obras traz diversas discussões sobre o impacto da tecnologia nos espaços educativos e no cotidiano, e nesse contexto o aprender sozinho nos espaços virtuais ganha destaque com a ascensão da Educação à Distância e suas modalidades, totalmente online ou semi-presencial, mas focada no Ensino Superior, que em seus cursos presenciais passa a adotar um percentual de aulas à distância, o que provoca críticas por parte da maioria dos alunos acostumados com as disciplinas ministradas presencialmente.

Embora os especialistas sinalizassem a importância da Educação à Distância, houve certa resistência e muitas instituições mantiveram seus projetos de implantação, num sentido de reduzir custos com a contratação de professores e outros gastos. O Ensino Superior dava um passo a mais em termos de se implantar novas modalidades de ensino e uso de recursos tecnológicos na Educação. Os recursos didáticos tecnológicos se inspiram nos tradicionais, só que com novas roupagens. Nesse novo contexto, a produção de videoaulas e ebooks, traz consigo também um novo ator do processo ensinoaprendizagem, o tutor, que na realidade atua como multitarefas.

Enquanto isso, a Educação Básica ainda engatinhava na implantação de recursos tecnológicos como ferramenta de ensino. A implantação de laboratório de informática nas escolas públicas foi lenta e numa análise global não ocorreu efetivamente por falta de investimentos na compra de equipamentos, falta de cursos de capacitação para professores e instalação de rede para suporte à conexão à internet.

Assim, os PCNs (BRASIL, 1998, p. 41) seguiam a ideia de associar a tecnologia ao ensino por meio da informática, colocando os computadores e as calculadoras como ferramentas desse processo em que lidar com as informações torna-se uma habilidade a ser desenvolvida e novos saberes oriundos desse cenário tecnológico exigem novas competências e aprendizagem contínua e muitas vezes de forma coletiva: 
O impacto da tecnologia na vida de cada indivíduo vai exigir competências que vão além do simples lidar com as máquinas. A velocidade do surgimento e renovação de saberes e de formas de fazer em todas as atividades humanas tornarão rapidamente ultrapassadas a maior parte das competências adquiridas por uma pessoa ao início de sua vida profissional. O trabalho ganha então uma nova exigência, que é a de aprender continuamente em um processo não mais solitário. $\mathrm{O}$ indivíduo, imerso em um mar de informações, se liga a outras pessoas, que, juntas, complementar-se-ão em um exercício coletivo de memória, imaginação, percepção, raciocínios e competências para a produção e transmissão de conhecimentos. Esse impacto da tecnologia, cujo instrumento mais relevante é hoje o computador, exigirá do ensino de Matemática um redirecionamento sob uma perspectiva curricular que favoreça o desenvolvimento de habilidades e procedimentos com os quais o indivíduo possa se reconhecer e se orientar nesse mundo do conhecimento em constante movimento. Para isso, habilidades como selecionar informações, analisar as informações obtidas e, a partir disso, tomar decisões exigirão linguagem, procedimentos e formas de pensar matemáticos que devem ser desenvolvidos ao longo do Ensino Médio, bem como a capacidade de avaliar limites, possibilidades e adequação das tecnologias em diferentes situações. (BRASIL, 1998, p. 41)

Anos mais tarde, em 2020, por conta da pandemia do COVID 19 e a suspensão das aulas presenciais, os recursos tecnológicos seriam os protagonistas do processo ensino-aprendizagem em todos os níveis de ensino, principalmente as plataformas de webconferência utilizadas para as aulas remotas, softwares educativos, o WhatsApp e telegram para formação de grupos com as turmas escolares para o envio de mensagens, plataformas de apoio ao ensino como AVA (Ambiente Virtual de Aprendizagem) e Google Classroom, notebooks, tablets, os aplicativos educativos contendo jogos, jogos online e canais do YouTube, entre outros, ferramentas essenciais para este novo cenário educacional.

Além do mais, é importante destacar que a Base Nacional Comum Curricular (BRASIL, 2018) incentiva a cultura digital por meio de duas de suas competências gerais, como podemos ver:

Valorizar e utilizar os conhecimentos historicamente construídos sobre o mundo físico, social, cultural e digital para entender e explicar a realidade, continuar aprendendo e colaborar para a construção de uma sociedade justa, democrática e inclusiva. Compreender, utilizar e criar tecnologias digitais de informação e comunicação de forma crítica, significativa, reflexiva e ética nas diversas práticas sociais (incluindo as escolares) para se comunicar, acessar e disseminar informações, produzir conhecimentos, resolver problemas e exercer protagonismo e autoria na vida pessoal e coletiva. (BRASIL, 2018, p. 09) 
Wilamis Micael de Araújo Aviz, Audrey Emmely Rodrigues Vasconcelos e Claudia de Oliveira Lozada O uso dos aplicativos Photomath e Toon Math no ensino de matemática

Por sua vez, o celular ganhou destaque como uma tecnologia móvel acessível e prática porque possui diversas funcionalidades como navegar na internet, assistir filmes e vídeos, baixar aplicativos e jogos, utilizar a calculadora, dentre outras.

Mas, nem sempre os alunos possuem os dispositivos móveis. Algumas pesquisas realizadas durante o ano de 2020 (quando iniciou a pandemia do COVID 19 e foram suspensas as aulas presenciais nas escolas) demonstraram que muitos alunos ou não possuíam o dispositivo móvel ou não possuíam o pacote de dados, tendo que retirar as atividades na escola, o que provocou também certo afastamento de muitos alunos das atividades escolares.

E sobre as tecnologias digitais móveis, é importante ressaltar que podem estimular $\mathrm{o}$ interesse pelas aulas, tornando o processo de aprendizagem mais dinâmico e possibilitando ao aluno acessar os conteúdos em outros momentos, fora do horário escolar:

\begin{abstract}
As tecnologias digitais móveis provocam mudanças profundas na educação presencial e a distância. Na presencial, desenraizam o conceito de ensinoaprendizagem localizado e temporalizado. Podemos aprender desde vários lugares, ao mesmo tempo, on e off-line, juntos e separados. Na educação a distância permitem o equilíbrio entre a aprendizagem individual e a colaborativa, de forma que os alunos de qualquer lugar podem aprender em grupo, em rede, da forma flexível e adequada para cada aluno. (MORAN, 2013, p. 30).
\end{abstract}

Considerando a afirmação de Moran (2013) esse tipo de tecnologia implica numa aprendizagem móvel, que se realiza em diversos momentos e espaços, com um alcance maior, cuja conexão é rápida, e pode integrar os alunos em ambientes colaborativos de aprendizagem, como em fóruns no AVA e grupos de WhatsApp nos quais são geradas discussões sobre o conteúdo e esclarecimentos de dúvidas. Inclusive a Organização das Nações Unidas para a Educação, a Ciência e a Cultura (UNESCO) apoia a aprendizagem móvel e a define da seguinte maneira:

Os aparelhos móveis (telefones celulares, smartphones, tablets, etc.) estão transformando o modo pelo qual nós nos comunicamos, vivemos e aprendemos. A aprendizagem móvel oferece formas modernas que ajudam no processo de aprendizagem por meio de aparelhos móveis, como notebooks, tablets, MP3 players, smartphones e telefones celulares. Devemos garantir que essa revolução digital torne-se uma revolução na educação promovendo uma aprendizagem inclusiva e de melhor qualidade em todos os lugares. (UNESCO, 2017, p. 01) 
Wilamis Micael de Araújo Aviz, Audrey Emmely Rodrigues Vasconcelos e Claudia de Oliveira Lozada $O$ uso dos aplicativos Photomath e Toon Math no ensino de matemática

A utilização da tecnologia digital móvel e a participação nos ambientes digitais de aprendizagem levam ao desenvolvimento de habilidades digitais (ZULKARNAIN, HELENI e THAHIR, 2020), tais como pesquisar, obter, criar, avaliar, organizar e compartilhar informações e conhecimento nos contextos digitais; trabalhar colaborativamente nos ambientes digitais e gerar interações que contribuam para compartilhar o conhecimento; autogerenciar seu processo de aprendizagem e refletir sobre o seu desenvolvimento; ter postura ética nos ambientes digitais de aprendizagem; criticidade e seletividade diante das informações e conhecimentos compartilhados; capacidade de adaptação à novos recursos que surgirem, entre outras.

Por outro lado, é preciso considerar os conhecimentos que os alunos trazem acerca dessa tecnologia digital móvel, partindo dos contextos onde eles as operam, as relações culturais que as impregnam, os hábitos de aprendizagem que possuíam anteriormente, partindo de uma racionalidade relevante:

Uma escola, sustentada em uma racionalidade relevante ante as novas tecnologias de informação, assumiria que a aprendizagem se realiza em múltiplas situações e cenários da vida cotidiana, e que, por isso, essa aprendizagem varia em sua importância, formalidade e legitimidade. (OROZO-GÓMEZ, 2002, p. 68)

A racionalidade da relevância ajuda na reconfiguração do processo ensinoaprendizagem, reestrutura os conteúdos, seleciona novos recursos didáticos e metodologias e extrai das vivências dos alunos, elementos importantes e que têm significado para a construção do conhecimento.

Assim, os aparelhos móveis se enquadram nessa racionalidade da relevância e se destacaram por serem portáteis e práticos, passando a ser uma tecnologia primordial na rotina escolar e na vida de crianças, jovens e adultos (ABREU, 2018). Por meio deles, o acesso aos aplicativos que contêm jogos educativos tornou-se mais célere, uma vez que podem ser facilmente baixados pela loja de aplicativos. Esses jogos, trazem uma abordagem lúdica e atrativa dos conteúdos, o que estimula o interesse pelas aulas, favorecendo também a busca de elaboração de estratégias de resolução mais criativas e ágeis, promovendo o desenvolvimento do raciocínio lógico e do cálculo mental.

Sendo assim, neste trabalho analisamos dois aplicativos para o ensino de Matemática na Educação Básica, pontuando suas características e benefícios. O primeiro destina-se ao ensino de Aritmética no Ensino Fundamental e o segundo é um aplicativo 
Wilamis Micael de Araújo Aviz, Audrey Emmely Rodrigues Vasconcelos e Claudia de Oliveira Lozada $O$ uso dos aplicativos Photomath e Toon Math no ensino de matemática

que propõe a resolução de questões matemáticas e pode ser utilizado em todos os níveis da Educação Básica e também no Ensino Superior.

Para a análise dos aplicativos, foi realizada uma pesquisa qualitativa (LÜDKE e ANDRÉ, 1986) com abordagem descritiva e analítica. A seleção dos aplicativos ocorreu em virtude das seguintes características: nível de Ensino (Educação Básica e Ensino Superior), funcionalidade (possuindo conteúdo matemáticos com os quais os alunos apresentam dificuldades, como é o caso da Aritmética no Ensino Fundamental e conteúdos de Cálculo no Ensino Superior) e facilidade de acesso (sem pagamento de taxas para acesso à determinados comandos do aplicativo). Após uma busca na Play Store e Google Play, selecionamos os aplicativos Toon Math e Photomath, que se encaixam nas características anteriormente citadas.

\section{O aplicativo Toon Math no ensino de Aritmética nos anos iniciais do Ensino Fundamental}

O aplicativo Toon Math Corrida Infinita é um jogo de Matemática no qual é possível revisar conceitos de Aritmética de maneira lúdica. Esse é um jogo que vai testar e aprimorar as habilidades matemáticas de quem o joga. Está disponível em Android e iOS com idioma português e o aluno poderá escolher o personagem que o representará no jogo.

O jogo baseia-se em correr e escapar de obstáculos e o objetivo é coletar moedas e realizar as operações aritméticas que surgem ao longo do caminho. Seu diferencial é que vem com componente educacional. Este é um jogo ótimo para pais e professores que querem revisar/ensinar crianças a somar, subtrair, multiplicar e dividir, assim como uma introdução à equação com uma variável, sem a utilização de letras, mas trabalhando com cálculo mental.

Aqui cabe considerar que a BNCC (BRASIL, 2018, p. 287) coloca a Álgebra como unidade temática nos anos iniciais e no $3^{\circ}$ ano por meio do objeto de conhecimento "relação de igualdade" introduz a noção intuitiva de incógnita, relacionando-o ao desenvolvimento da habilidade "EF03MA11 - Compreender a ideia de igualdade para escrever diferentes sentenças de adições ou de subtrações de dois números naturais que resultem na mesma soma ou diferença". E o Toon Math abre caminho para se trabalhar 
esse objeto do conhecimento e sua respectiva habilidade citada pela BNCC (BRASIL, 2018) como veremos mais adiante.

Além das quatro operações básicas, o jogo conta com níveis: muito fácil, fácil, normal, difícil e muito difícil. Nos níveis muito fácil e fácil as operações são simples contendo os dois operandos. Nos modos normal, difícil e muito difícil virão operações com uma incógnita, similar a uma equação de grau 1. O jogo possui um menu no qual é possível definir quais operações matemáticas serão oferecidas durante a partida, assim como seu nível de dificuldade. Sendo assim, cabe ao professor definir esses itens no planejamento da aula na qual utilizará esse recurso, considerando o perfil da turma.

Figura 1 - Configurações do jogo e seus níveis de dificuldade

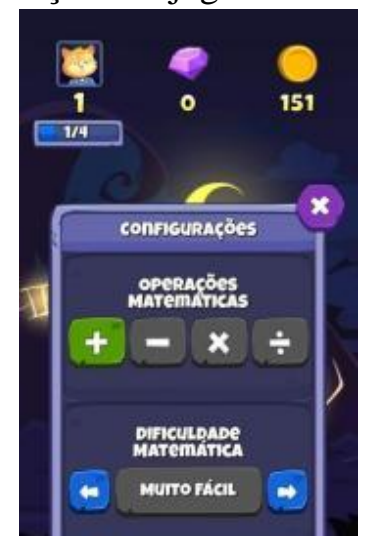

Fonte: Os Autores (2021)

Como falado anteriormente, o referido jogo destina-se à revisão/ensino das operações básicas da Matemática, logo é recomendado sua utilização nos anos iniciais, do $1^{\circ}$ ao $5^{\circ}$ ano do Ensino Fundamental. Recomendamos usar os níveis muito fácil e fácil para os alunos do $1^{\circ}$ ao $3^{\circ}$ ano e os demais níveis para alunos do $4^{\circ}$ ao $5^{\circ}$ ano. Também poderá ser utilizado no $6^{\circ}$ ano do Ensino Fundamental para revisar as operações aritméticas.

No decorrer do jogo, virão alguns objetos coletáveis, como por exemplo, ficar com o personagem maior, moedas em dobro, escudo, e ao capturá-los, surgirá uma caixa com atividade para o jogador. Em seguida, aparecerão possíveis soluções para a operação na tela, bastando arrastar o personagem para a resposta correta como podemos ver na figura abaixo: 
Figura 2 - Adição

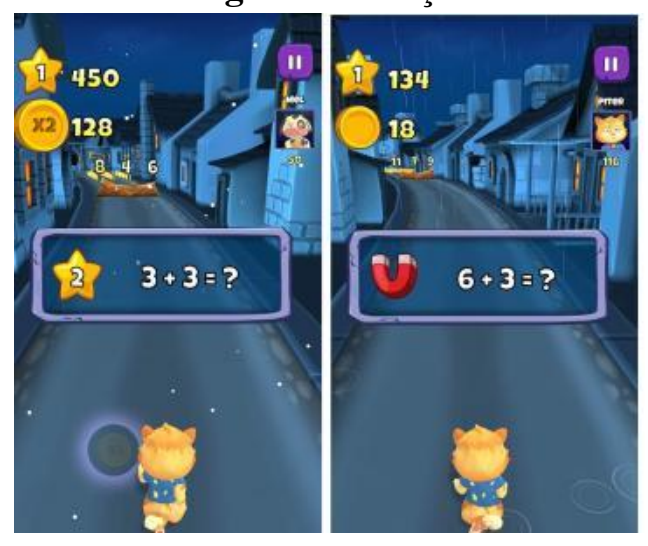

Fonte: Os Autores (2021)

A medida em que o jogador avança no jogo, as operações irão ficando mais intensas e rápidas, fazendo com que o aluno desenvolva agilidade em realizar operações matemáticas mentalmente, sem a necessidade de registrá-las no caderno, por exemplo.

Figura 3 - Multiplicação e divisão

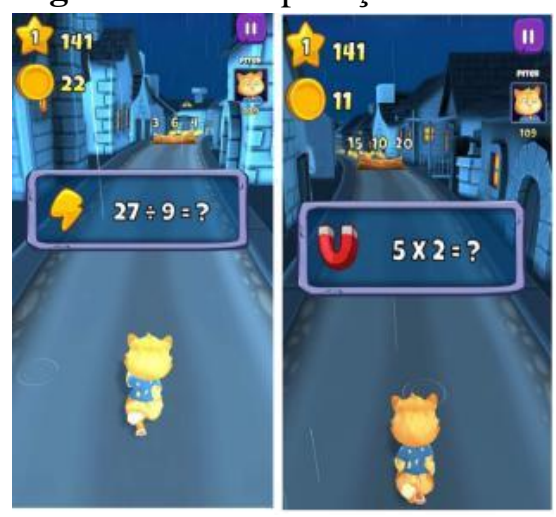

Fonte: Os Autores (2021)

Se o jogador utilizar as dificuldades normal, difícil e muito difícil, virão operações envolvendo uma variável na equação a ser resolvida, ou seja, no lugar de um dos operandos haverá uma incógnita representada por um ponto de interrogação. Muitos livros chamam esse método de operação com números ocultos. 


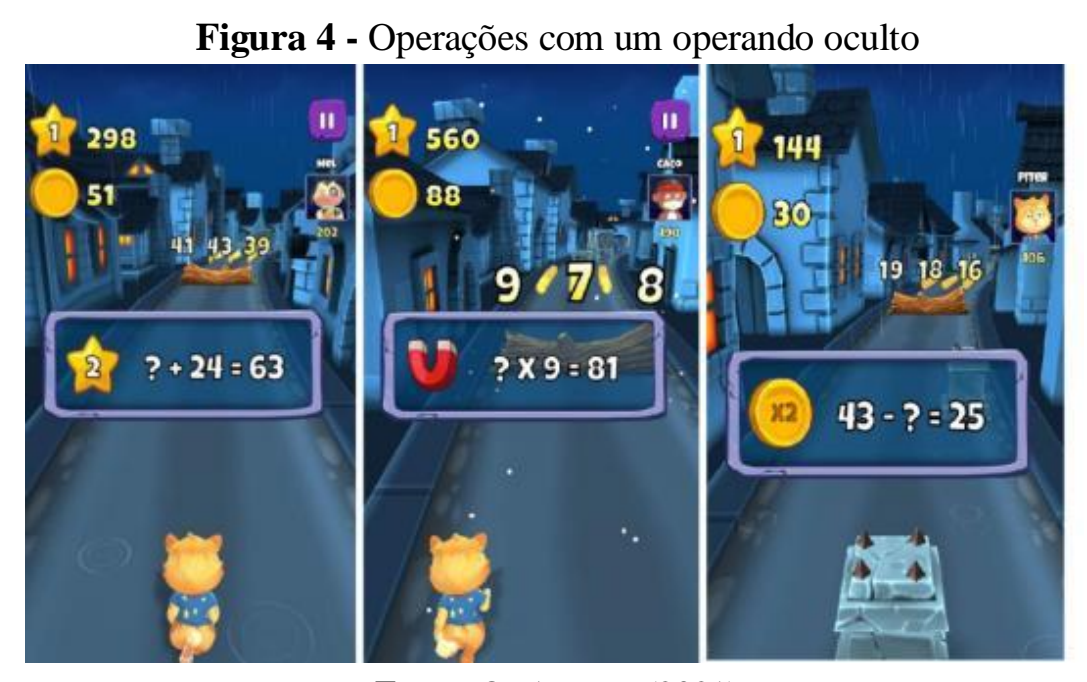

Fonte: Os Autores (2021)

Podemos dizer que nesses níveis de dificuldade, o aluno terá um contato inicial com a equação do primeiro grau, tendo que realizar o cálculo mentalmente sem o auxílio de calculadora ou papel. Numa análise global, o jogo é fácil de se acessar, possui uma interface de fácil manuseio, está no idioma português e as atividades propostas são conduzidas por um personagem dentro de um cenário. Auxilia no desenvolvimento do cálculo mental, na coordenação motora e também na melhoria da atenção, uma vez que o aluno tem que ficar atento aos obstáculos que podem fazer com que colida com eles e o jogo se encerre.

No entanto, o Toon Math apresenta os fatos básicos (as continhas), sem atrelálas à uma situação-problema, privilegiando os procedimentos matemáticos. É essencial que o professor planeje a aula com o uso desse aplicativo, agregando outras atividades àquelas que são propostas pelo Toon Math com situações-problema e também para que o aluno perceba o caráter educativo deste recurso nas aulas de Matemática e não tenha uma visão equivocada de que o aplicativo se direciona à diversão e lazer.

\section{O uso do aplicativo Photomath no ensino de Matemática na Educação Básica e Ensino Superior}

O Photomath é um dos aplicativos educativos mais baixados pelos alunos, e está disponível para os sistemas iOS e Android. Apesar de ser recomendado para a faixa etária acima dos 4 anos, ele tem maior utilidade para os alunos que estão se preparando para prestar vestibulares ou realizar avaliações. O aplicativo aborda conteúdos que vão desde a Educação Básica até o Ensino Superior. 
A função dele é resolver questões e problemas matemáticos através da digitalização das equações, sejam elas impressas ou escritas à próprio punho, por meio da câmera de um smartphone ou tablet. A conexão com a internet é necessária somente para baixar o aplicativo, após a instalação, ele pode funcionar normalmente sem que o aparelho esteja conectado à internet.

Embora seja um aplicativo de uso muito intuitivo, dentro de sua interface, há a possibilidade de acessar um breve manual de uso, caso o aluno sinta dificuldade ou tenha dúvida a respeito das funções existentes.

É possível encontrar três vídeos explicativos: o primeiro se refere ao ajuste da câmera, demonstrando como capturar a questão matemática dentro da linha vermelha ajustando a dimensão do visor; o segundo mostra a utilização da calculadora avançada, exibindo outras opções de teclado quando alguma tecla com um ou mais pontos vermelhos é clicada; e o terceiro indica como acessar o histórico, onde contêm os problemas e questões que já foram digitalizados e resolvidos em algum momento durante o uso.

Figura 5 - Aplicativo Photomath

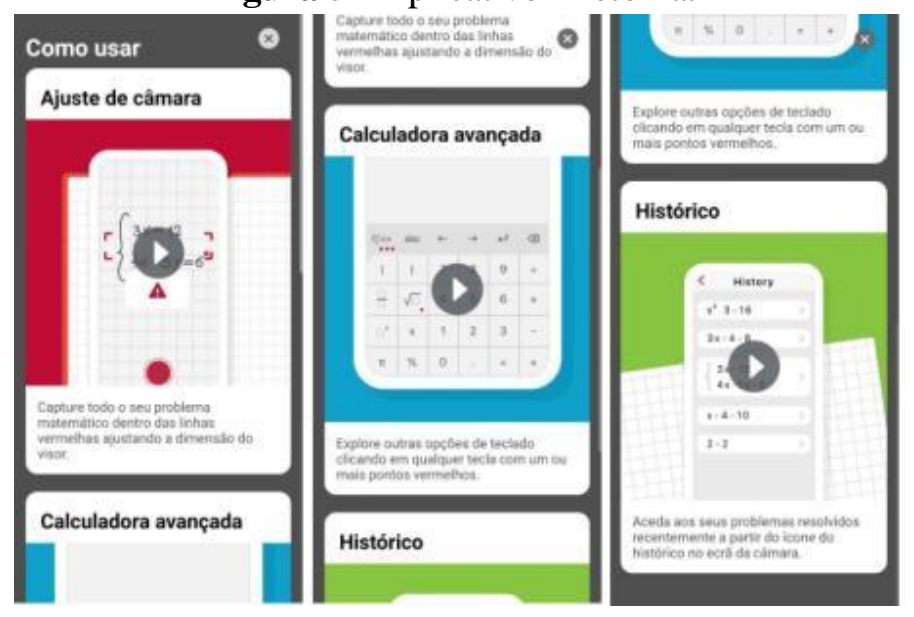

Fonte: Os Autores (2021)

Após digitalizar a questão, o aplicativo explica passo a passo como é resolvida, podendo também apresentar mais de uma resolução, caso exista. Por isso, a ferramenta pode ser considerada um meio para intensificar o aprendizado, pois através dela o aluno é capaz de compreender os procedimentos utilizados para a resolução da questão. 
Figura 6 - Usando o aplicativo Photomath para resolução da questão

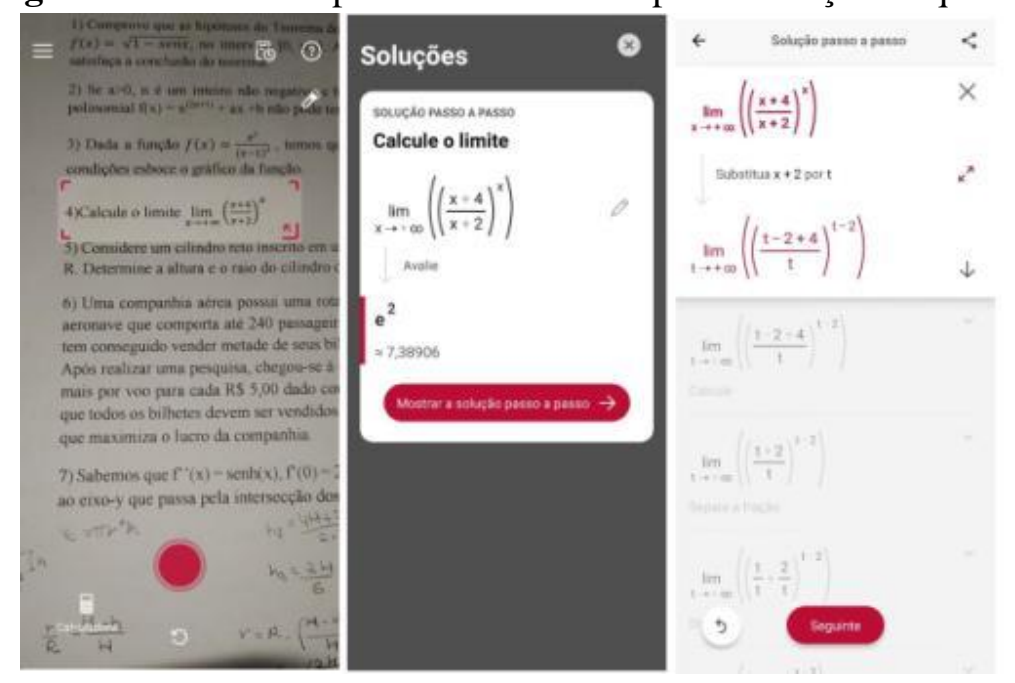

Fonte: Os Autores (2021)

Além da digitalização das equações, há a opção de digitá-las através da calculadora existente no aplicativo, sendo esta mais completa que a convencional disponibilizada nos aparelhos, pois nela é possível realizar cálculos mais complexos, como limites e derivadas.

Figura 7 - Aplicativo Photomath e a calculadora

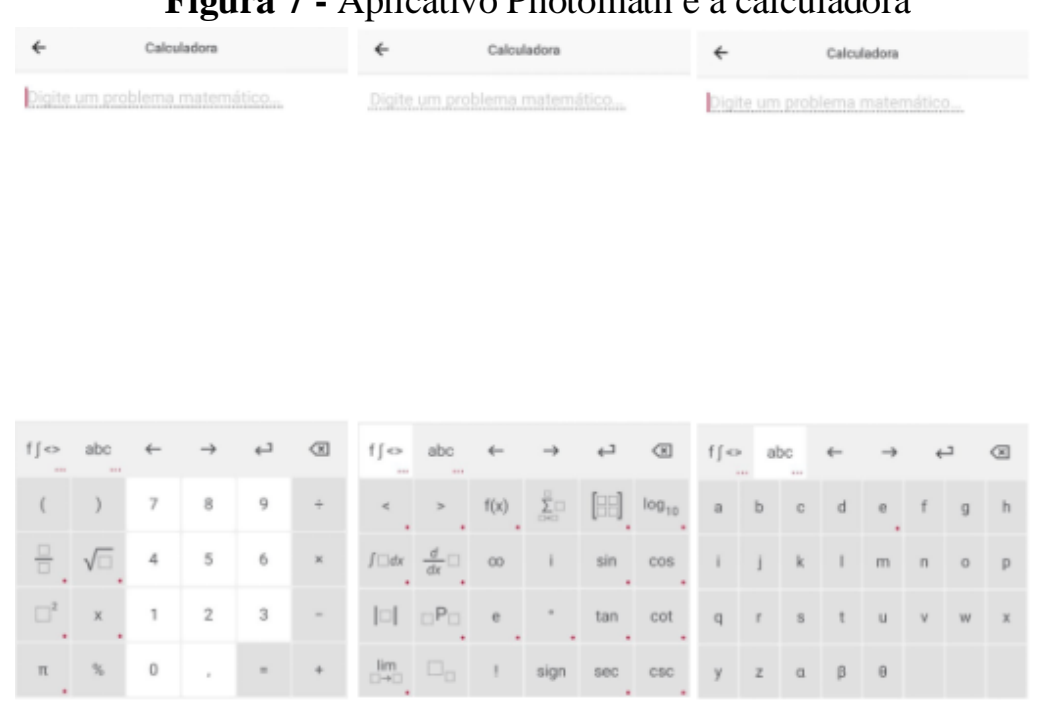

Fonte: Os Autores (2021)

Por fim, o aplicativo tem como objetivo apresentar as informações corretas acerca dos problemas e questões propostas para ajudar os alunos a processá-los e entendê-los, auxiliando o aprendizado através da análise da resolução obtida, de modo com que os 
Wilamis Micael de Araújo Aviz, Audrey Emmely Rodrigues Vasconcelos e Claudia de Oliveira Lozada O uso dos aplicativos Photomath e Toon Math no ensino de matemática

alunos consigam identificar possíveis erros, fazendo com que não os cometam futuramente.

Numa análise global, o aplicativo exige a conjunção de várias ações operacionais para que a resolução das questões matemáticas seja efetuada, como digitalização e alinhamento no visor, mas o vídeo explicativo e o manual podem ajudar nesse sentido e aos poucos, o aluno vai automatizando o seu acesso, de maneira que com o tempo, o manuseio do aplicativo se torne mais familiar.

É necessário que o professor planeje a aula para o uso desse aplicativo, propondo atividades que tragam problemas desafiadores e problemas abertos nos quais os alunos tenham que elaborar suas heurísticas para resolvê-los, utilizando a criatividade e justificando as resoluções, propondo que alunos apresentam as resoluções na lousa e expliquem para a turma. Dessa forma, pretende-se que o aluno não mecanize procedimentos matemáticos que são típicos de exercícios matemáticos e que são em grande parte o foco do Photomath, mas perceba que os exercícios são tipos de tarefas (PONTE, 2005) que desenvolvem determinadas habilidades e que são necessários outros tipos de tarefas matemáticas para que outras habilidades sejam desenvolvidas.

Os dois aplicativos analisados permitem retomar os conteúdos matemáticos, o que promove maior fixação de conceitos e procedimentos.

Por fim, cabe mencionar que o uso dos aplicativos implica em se planejar a aula de Matemática, conjugando com outras atividades para que não se resuma em uma atividade pontual e isolada, sem conexão com os objetos de conhecimento e habilidades e competências previstas pela BNCC (BRASIL, 2018).

\section{Considerações finais}

Por muito tempo se utilizou o quadro como referência para o ensino e com o avanço da tecnologia se tornou comum o uso de datashow e desktops para apresentação de aulas expositivas, agregando-as com outros recursos tecnológicos, ainda mais diversificados como foi no caso da pandemia em 2020.

Assim, a utilização dos sistemas operacionais embarcados móveis (por meio dos sistemas operacionais Android e iOS presentes nos celulares) possibilita o acesso à recursos digitais para um ensino lúdico nas aulas de Matemática, além de possibilitar que 
Wilamis Micael de Araújo Aviz, Audrey Emmely Rodrigues Vasconcelos e Claudia de Oliveira Lozada O uso dos aplicativos Photomath e Toon Math no ensino de matemática

o próprio aluno a qualquer momento abra o aplicativo em sua casa e revise o conteúdo trabalhado em sala de aula presencial ou virtual.

É notório que muitos alunos apresentem dificuldades na compreensão de conteúdos matemáticos e os aplicativos podem auxiliar no processo ensinoaprendizagem, pois tornam as aulas mais dinâmicas e interessantes, sendo primordial que seu uso esteja aliado a um planejamento prévio da aula.

Calder e Murphy (2018) explicam que os aplicativos possibilitam múltiplas representações de um conteúdo e têm a capacidade de vincular e promover a interação simultânea do aspecto visual, simbólico e numérico de forma dinâmica, além de mudar a definição do que é espaço de aprendizagem, pois em virtude da mobilidade dos celulares, a aprendizagem não está mais em um determinado lugar ou tempo, mas pode ocorrer a qualquer hora e em qualquer lugar. Os autores também colocam que o uso de aplicativos no ensino de Matemática traz a ideia de personalização, ou seja, o professor pode escolher aplicativos que atendam às necessidades específicas de aprendizagem dos alunos e, deste modo, como colocam Calder e Murphy (2018) moldar a experiência de aprendizagem.

Os aplicativos aqui expostos são de fácil manuseio e contribuem para a aprendizagem de Matemática desde a Educação Básica até o Ensino Superior, auxiliando na compreensão conceitual e procedimental e no desenvolvimento de habilidades e competências matemáticas.

Por fim, percebemos o quão importante é a utilização das TDICS (Tecnologias Digitais de Informação e Comunicação) no processo ensino-aprendizagem de Matemática e ficou bastante evidente isso durante o período pandêmico em 2020 com aulas remotas, e mesmo em 2021 com parte das escolas em ensino remoto e outra parte com ensino híbrido, a relevância da utilização dos recursos tecnológicos ainda prepondera e esperamos que este atual contexto leve à adoção de políticas públicas para equipar as escolas, capacitar os professores acerca do uso das TDICs e incorporar efetivamente o uso desses recursos nas práticas pedagógicas e no cotidiano escolar.

\section{Referências}

ABREU, J. D. de. Aprendizagem móvel: explorando a Matemática por meio de aplicativos educacionais em smartphones. 2018. 233f. Dissertação (Programa de PósGraduação em Ensino de Ciências e Educação Matemática - PPGECEM) Universidade Estadual da Paraíba, Campina Grande, 2018. 
Wilamis Micael de Araújo Aviz, Audrey Emmely Rodrigues Vasconcelos e Claudia de Oliveira Lozada O uso dos aplicativos Photomath e Toon Math no ensino de matemática

BRASIL. Ministério da Educação. Secretaria da Educação Fundamental. Parâmetros curriculares nacionais: matemática. Brasília: MEC/SEF, 1998.

Base nacional comum curricular. Brasília: MEC/Secretaria de Educação Básica, 2018.

CALDER, N., CAMPBELL, A. Using mathematical Apps with reluctant learners. Digit Exp Math Educ. v. 2, p.50-69, 2016.

, MURPHY, C. Using apps for teaching and learning mathematics: a socio technological assemblage. Disponível em: https://files.eric.ed.gov/fulltext/ED592503.pdf. Acesso em: 6 abr. 2021.

LÉVY, P. A inteligência coletiva: por uma antropologia do ciberespaço. $4^{\mathrm{a}}$ ed. São Paulo: Loyola, 2003.

Cibercultura. 2a ed. São Paulo: Editora 34, 2000.

LUDKE, M.; ANDRÉ, M. E. D. A. Pesquisa em educação: abordagens qualitativas. São Paulo: EPU, 1986.

MORAN, J. M. Ensino e aprendizagem inovadores com tecnologias. In: MORAN, J.M.; MASETTO, M. T.; BEHRENS, M.A. (Orgs). Novas tecnologias e mediação pedagógica. $21^{\mathrm{a}}$ ed. Campinas: Papirus, 2013. p. 11-66.

OROZCO-GÓMEZ, G. Comunicação, educação e novas tecnologias: tríade do século XXI. Revista Comunicação \& Educação, 23, p. 57-70, 2002.

PHOTOMATH SCAN SOLVE. Photomath. Disponível em: <https://photomath.app/pt>. Acesso em: 18 fev. 2021.

PLAY GOOGLE STORE. Toon Math: jogos de matemática e corrida infinita. Disponível em:

<https://play.google.com/store/apps/details?id=com.closeapps.mathrun\&hl=pt_BR $>$. Acesso em: 16 fev. 2021.

PONTE, J. P. Gestão curricular em Matemática. In: Grupo de Trabalho de Investigação (Ed.). O professor e o desenvolvimento curricular. Lisboa, Portugal: Associação de Professores de Matemática, 2005. p. 11-34

UNESCO. Aprendizagem móvel. Disponível em:

http://www.unesco.org/new/pt/brasilia/communication-and-information/accesstoknowledge/ict-in-education/mobile-learning/. Acesso em: 6 mar. 2021.

ZULKARNAIN, Z., HELENI, S., THAHIR, M. Digital literacy skills of math students through e-learning in COVID-19 era: a case study in Universitas Riau. Journal of Physics: Conference Series, v. 1663, p. 01-09, 2020. 